\title{
Evaluating Attribution of Responsibility and Minimization by Male Batterers: Implications for Batterer Programs
}

\author{
Marisol Lila*, ${ }^{*}$, Juan Herrero ${ }^{2}$ and Enrique Gracia ${ }^{1}$ \\ ${ }^{I}$ Department of Social Psychology, University of Valencia, Spain \\ ${ }^{2}$ Department of Psychology, University of Oviedo, Spain
}

\begin{abstract}
Men arrested and condemned for intimate partner violence assaults tend to use external attributions to justify their behavior and tend to minimize the severity of their violent acts. Responsibility assumption is one of the main goals in many batterer programs because it could facilitate behavioral changes and reduce the dropout rate. In the current study, first we aim to create two scales to assess attribution of responsibility and minimization of incidents of partner violence, and second, to classify batterers based on their levels of minimization and their attributions of responsibility. Participants were 119 male batterers attending to the first assessment session of a court mandated batterer intervention program in the community. The analyses showed appropriate psychometric characteristics for both scales. The scores obtained allowed us to identify two types of participants in the study.
\end{abstract}

\section{INTRODUCTION}

Intimate partner violence against women (IPVAW) is a social and public health problem as well as a human rights abuse with a high prevalence worldwide. The World Health Organization's [1] offers a summary of 48 population-based surveys from around the world in which $10 \%$ to $69 \%$ of women reported being physically assaulted by an intimate partner. In western countries IPVAW affects many women at some point in their lives [2-6]. Furthermore, the impact of IPVAW on women's physical and mental health, both in the short and long term, and the wider effects of IPVAW on families, communities, and society, makes it a public health priority [7-9]. Prevalence data in Spain, where this study was conducted, are similar to other Western countries, with estimates ranging from $4.0 \%$ to $12.4 \%$ [10-12]. Given the high prevalence of this problem, it is important to improve our ability to assess, prevent, and intervene in intimate partner violence [13].

\section{ATTRIBUTION OF RESPONSIBILITY AND MINI- MIZATION}

Frequently, men arrested and condemned for IPVAW show a lack of responsibility assumption [14-17]. This denial of personal responsibility is a basic trait of IPVAW offenders [18]. Male batterers often use external attributions such us their partner's personality or behavior, stress or economic and occupational difficulties, to justify their behavior [1921]. Also, compared to nonviolent men, batterers are more likely to blame their partners for their marital conflicts [2223 ]. Furthermore, their jealousy makes them often to attribute more negative motivations to women's behaviors [2325].

*Address correspondence to these authors at the Department of Social Psychology, Facultad de Psicología, Universidad de Valencia, Avda. Blasco Ibáñez 21, 46010 Valencia, Spain; E-mail: marisol.lila@uv.es
Also, batterers commonly minimize the severity of their violent acts or completely deny the incident [14-26], and argue "self-defense" to justify their own acts [27]. According to professionals interviewed in a study conducted by Edin, Lalos, Högberg, and Dahlgren [28] in Sweden, male batterers "tend to diminish what has happened, seem not to fully understand the consequences of their violent behavior, and are thus able to justify themselves and even portray themselves as victims... Men for instance might claim that women cheated on them or offended them emotionally or explain that they had both been fighting or that they had reacted to their partner hitting them first or else she was furious, hysterical, and acted badly so he was forced to keep a firm hold on her and to grapple and beat her".

In addition, as Henning and Holdford [15] point out, IPVAW offenders are in many cases skilled at presenting themselves in socially favourable ways in multiple scenarios (self-report questionnaires, clinical interviews, treatment sessions) [29]. Effects of social desirability on reporting of relationship aggression and attributions have been found in previous studies [18, 30-32].

\section{BATTERER PROGRAMS AND ASSUMPTION OF RESPONSIBILITY}

Batterer intervention programs are an integral part of any comprehensive approach to IPVAW [33]. The vast majority of batterer intervention programs acknowledge the importance of making offenders aware of their responsibility for the violent behavior. Moreover, standards of good practice in batterer intervention programs usually work with misattributions such as victim blaming, denial and minimization. Encouraging batterers to take personal responsibility for their violent behavior is also a critical intervention goal $[18,34]$. For example, in programs based on the Duluth Model [35] batterers have to face up the consequences of their own behavior, accept responsibility for the harm done and eliminate the justifications and rationalizations in relation to their behavior [36-37]. Denial, minimization and victim blaming 
strategies used by batterers have been a matter of concern because its association with increased risk of recidivism [16]. Many treatment programs assume that men who deny their responsibility will have a high probability to continue abusing their partners [33, 35, 38-39]. However, little research attention has been paid to the relationship between recidivism and responsibility assumption. Moreover, the scant research on relationship between recidivism and responsibility assumption and minimization provide mixed and inconsistent results [15, 39-41]. On the other hand, some research has shown that high levels of victim-blaming are associated with increased intimate partner abuse [42]. Studies on attributions in relationships show that men who have been violent in their relationships tend to view their partners as critical, rejecting, and intentionally malicious, and tend to blame their partners for difficulties [43-45]. Finally, with regard to minimization, as Scott and Straus [18] point out, individuals with prior experience of intimate partner violence are more likely to minimize the extent and impact of low-level abusive behaviors [46] and to be accepting aggression in relationships [47-48]. Furthermore, and of utmost importance for batterer programs, men who avoid taking responsibility for their violent behavior will be less motivated to change and will be in higher risk of premature treatment termination [49-51].

\section{THE PRESENT STUDY}

Despite the importance to asses carefully all these cognitive distortions and management impressions by male batterers, the studies and measures on these issues remain scarce [18]. Furthermore, in Spain, except for few exceptions, there is virtually no tradition in studies about batterer programs, and almost no psychometrically sound evaluation instruments are available. In the current study, firstly we show the psychometric characteristics of two scales assessing, respectively, attribution of responsibility and minimization of incidents of partner violence against women among male batterers. Secondly, we used this scales to classify batterers based on their levels of minimization and their attributions of responsibility in order to identify specific interventions needs. Therefore, the twofold aims of the study are:

1) the analysis of the psychometric properties of two scales measuring attribution of responsibility and minimization.

2) the clustering of individuals regarding their levels of victim-blaming, self-defense justifications, selfattributions of blame, and minimization to evaluate if there was any meaningful profile in attributions of responsibility and minimization for male batterers.

\section{METHODOLOGY}

\section{Participants and Procedure}

Participants in this study were 119 male batterers attending to the first assessment session of a court mandated batterer intervention program in the community. This first assessment session aimed to ensure that some minimum requirements were met to take part in the program. As criteria for inclusion, the program established that: a) no substance or alcohol abuse was present; b) no presence of severe psychopathology; c) no indication of high levels of aggressive behavior that could put at risk the program personnel. Male batterers completed paper-and-pencil tests in a large group room under supervision of program personnel. Questionnaires were read to the men when necessary. Table 1 presents descriptive statistics of socio-demographic variables.

Table 1. Descriptive Statistics for Socio-Demographic Variables in the Sample $(\mathrm{N}=119)$

\begin{tabular}{|c|c|c|}
\hline & $\mathbf{n}$ & $\%$ \\
\hline \multicolumn{3}{|l|}{ Age } \\
\hline ....21-30 & 36 & 30.2 \\
\hline ....31-40 & 39 & 32.8 \\
\hline$\ldots 41-50$ & 34 & 28.6 \\
\hline ....51-60 & 7 & 5.8 \\
\hline ...61-70 & 3 & 2.6 \\
\hline \multicolumn{3}{|l|}{ Country } \\
\hline ....Spain & 68 & 57.1 \\
\hline ....Latin-America & 33 & 27.7 \\
\hline ....Other & 18 & 15.2 \\
\hline \multicolumn{3}{|l|}{ Educational Level } \\
\hline $\begin{array}{l}\text {....No educational } \\
\text { background }\end{array}$ & 12 & 10.3 \\
\hline ....Elementary school & 52 & 44.8 \\
\hline ....High school & 41 & 35.3 \\
\hline ....University Studies & 11 & 9.6 \\
\hline \multicolumn{3}{|l|}{ Employment } \\
\hline ....Employed & 72 & 61.0 \\
\hline ....Unemployed & 44 & 49.0 \\
\hline
\end{tabular}

Although the age ranged between 21 and 70 years old, most of participants were between 21 and 50 years old (about $71 \%$ ). More than a half of participants were Spaniards $(57.1 \%)$ while the remaining were immigrants. Among immigrants, mostly were from Latin-American countries $(27.7 \%)$, and $15.2 \%$ of participants were from other countries, mainly from Eastern Europe and Africa. Educational level was low with more than $50 \%$ of participants with elementary education or lower. Most of participants were employed at the time of the study $(61 \%)$.

\section{MEASURES}

\section{Attribution of Responsibility}

An 8-item scale was specifically created for this study to evaluate participants' attributions as to why they have been convicted for IPVAW. To do so, we reviewed previous work identifying male batterers' attributions [15, 52]. Also, we gathered information from experienced personnel in the evaluation of convicted males for IPVAW. The attribution of responsibility scale was developed to be self-administered and all items were framed within the following presentation: you are in a court mandated batterer program because you were convicted for intimate partner violence against woman. Then, participants were asked to estimate the degree of agreement with 8 items in a 0-99 response scale, being 0 completely disagree and 99 completely agree. The Attribu- 
tion of Responsibility Scale comprises three dimensions theoretically relevant and frequently studied in the literature on male batterers programs:

1) Victim-blaming assesses the degree to which the subject put the blame for his situation on personal characteristics or behavior of the victim (I am in this situation due to a false report; I am here because of the lies and exaggerations of my partner; the aggressive character, lack of control, nervousness or psychological problems of my partner are the reasons why I am in this situation).

2) Self-defense evaluates the degree to which the subject attributes his situation to an act of self-defense ( $\mathrm{am}$ in this situation because I acted in self-defense; I am here because I defended myself from my partner's aggressions).

3) Self-attribution of blame comprises three items that assess the degree to which the subject assume that his personal characteristics or behaviors are the reason why he is convicted for IPVAW (Alcohol or substance abuse is the reason why I am in this situation; I am in this situation because of my jealously; my character -aggressiveness, impulsivity, lack of control, nervousness, psychological problems, etc.- is the reason why I am in this situation).

\section{Minimization}

We created a 4-item scale that evaluates the degree to which the subject minimize the behavior that led him to be convicted (The reason why I am here is because the Law gets involved in private matters; I am in this situation for doing things that I have seen in my family; I am here because nowadays "domestic violence" is a label applied to trivial things; I am in this situation for doing things that in my family are considered unimportant).

\section{Social Desirability}

To evaluate the tendency to respond in a socially desirable fashion we used the Crowne-Marlowe scale [53]. This

Table 2. Principal Component Analysis, Internal Consistency and Pearson Correlations with Social Desirability

\begin{tabular}{|c|c|c|c|c|}
\hline & \multicolumn{3}{|c|}{ Attribution of Responsibility Scale ${ }^{1}$} & \multirow[t]{2}{*}{ Minimization Scale $^{2}$} \\
\hline & Victim-Blaming & Self-Defense & Self-Attribution of Blame & \\
\hline \multicolumn{5}{|l|}{ Attribution of Responsibility } \\
\hline I am in this situation due to a false report & .80 & & & \\
\hline $\begin{array}{l}\text { I am here because of the lies and exaggerations of my part- } \\
\text { ner }\end{array}$ & .82 & & & \\
\hline $\begin{array}{l}\text { The aggressive character, lack of control, nervousness or } \\
\text { psychological problems of my partner are the reasons why I } \\
\text { am in this situation }\end{array}$ & .79 & & & \\
\hline I am in this situation because I acted in self-defense & & .87 & & \\
\hline $\begin{array}{l}\text { I am here because I defended myself from my partner's } \\
\text { aggressions }\end{array}$ & & .83 & & \\
\hline $\begin{array}{l}\text { Alcohol or substance abuse is the reason why I am in this } \\
\text { situation }\end{array}$ & & & .75 & \\
\hline I am in this situation because of my jealously & & & .75 & \\
\hline $\begin{array}{l}\text { My character (aggressiveness, impulsivity, lack of control, } \\
\text { nervousness, psychological problems, etc.) is the reason why } \\
\text { I am in this situation }\end{array}$ & & & .60 & \\
\hline \multicolumn{5}{|l|}{ Minimization } \\
\hline $\begin{array}{l}\text { The reason why I am here is because the Law gets involved } \\
\text { in private matters }\end{array}$ & & & & .80 \\
\hline $\begin{array}{l}\text { I am in this situation for doing things that } \mathrm{I} \text { have seen in my } \\
\text { family }\end{array}$ & & & & .67 \\
\hline $\begin{array}{l}\text { I am here because nowadays "domestic violence" is a label } \\
\text { applied to trivial things }\end{array}$ & & & & .56 \\
\hline $\begin{array}{l}\text { I am in this situation for doing things that in my family are } \\
\text { considered unimportant. }\end{array}$ & & & & .57 \\
\hline Internal consistency (Cronbach’s alpha) & .78 & .79 & 60 & 60 \\
\hline Pearson correlations with Social Desirability & $.14 \mathrm{~ns}$ & $-.14 \mathrm{~ns}$ & $-.29 * *$ & $-.15 \mathrm{~ns}$ \\
\hline
\end{tabular}

${ }^{1}$ Loadings from the rotated solution (Promax).

${ }^{2}$ Loadings from the unrotated solution. 
10-item scale has been used in previous research with similar samples to assess the degree to which responses are biased because the subject is trying to present himself in a socially desirable fashion.

\section{RESULTS}

To ascertain if the two scales were multidimensional or unidimensional we first run a series of Principal Component Analyses. For the Attribution of Responsibility scale we found an underlying structure of three distinct components. These three components were then obliquely rotated (Promax) because the three theoretical dimensions were a priori related. For the Minimization scale we found a onecomponent solution, so there was no further need to rotate this component.

In Table 2 we present results for Principal component Analyses for the two scales along with their internal consistency and their relationships with social desirability. Regarding the Attribution of Responsibility Scale, the empirical structure found clearly reflects the three theoretical dimensions hypothesized: victim-blaming, self-defense, and selfattribution of blame. All of the loadings are greater than .50 and no cross-loadings greater than .45 were found, indicating that each item is clearly identified with only one component. Internal Consistency (Cronbach's alpha $=.70$ ) is moderate for the complete scale, while the corresponding alphas for the subscales ranges from .60 to .79 .

None of the scores are biased by social desirability except for self-attribution of blame $(r=-.29, p<.01)$. This finding suggests that in higher levels of social desirability there is a tendency to show lower levels of self-attribution of blame. The lack of statistical relationship of the two remaining dimensions of the Attribution of Responsibility Scale with social desirability also seems to suggest that victimblaming and self-defense responses were relatively unbiased in our participants.

Regarding the Minimization Scale, the four items clearly loaded in one dimension with coefficients greater than .55 . Its internal consistency is moderate $(\alpha=.60)$ and the scale score does not seem to be affected by social desirability ( $\mathrm{r}=$ -.15, n.s.)

In Table 3 we present the descriptive statistics for the 12 items of the Attribution of Responsibility and Minimization Scales. Overall, the items that obtained a higher degree of agreement were those of victim-blaming, all of them above 50. In this sense, the item with the greater mean is $I$ am in this situation because of the lies and exaggerations of my partner $(\mathrm{M}=61.94)$.

Also, those items that reflect self-attribution of blame obtained the greater disagreement in the sample, specifically the item I am in this situation because of my jealously $(\mathrm{M}=$ 18.38). Overall, both self-attributions of blame and selfdefense items registered the higher levels of disagreement in the sample.

Although item variability across subjects is moderate, as indicated by their standard deviations, these results seem to

Table 3. Means and Standard Deviations for Scales Items $(\mathbf{N}=119)$

\begin{tabular}{|c|c|c|}
\hline Items & Mean & Standard Deviation \\
\hline \multicolumn{3}{|l|}{ Attribution of Responsibility } \\
\hline \multicolumn{3}{|l|}{ Victim-Blaming } \\
\hline I am in this situation due to a false report & 50.76 & 42.53 \\
\hline I am here because of the lies and exaggerations of my partner & 61.94 & 39.24 \\
\hline $\begin{array}{l}\text { The aggressive character, lack of control, nervousness or psychological problems of my partner are the reasons } \\
\text { why I am in this situation }\end{array}$ & 52.82 & 37.54 \\
\hline \multicolumn{3}{|l|}{ Self-Defense } \\
\hline I am in this situation because I acted in self-defense & 28.81 & 38.27 \\
\hline I am here because I defended myself from my partner's aggressions & 31.54 & 39.89 \\
\hline \multicolumn{3}{|l|}{ Self-attribution of blame } \\
\hline Alcohol or substance abuse is the reason why I am in this situation & 25.28 & 36.68 \\
\hline I am in this situation because of my jealously & 18.38 & 30.91 \\
\hline $\begin{array}{l}\text { My character (aggressiveness. impulsivity. lack of control. nervousness. psychological problems. etc.) is the } \\
\text { reason why I am in this situation }\end{array}$ & 29.22 & 36.72 \\
\hline \multicolumn{3}{|l|}{ Minimization } \\
\hline The reason why I am here is because the Law gets involved in private matters & 18.82 & 30.93 \\
\hline I am in this situation for doing things that I have seen in my family & 9.41 & 26.05 \\
\hline I am here because nowadays "domestic violence" is a label applied to trivial things & 39.78 & 40.98 \\
\hline I am in this situation for doing things that in my family are considered unimportant. & 47.88 & 41.11 \\
\hline
\end{tabular}


Table 4. Pearson Correlations Sub-Scales for Attribution of Responsibility and Minimization

\begin{tabular}{|l|c|c|c|}
\hline & \multicolumn{3}{|c|}{ Attribution of Responsibility Scale } \\
\hline \hline Attribution of Responsibility & Victim-Blaming & Self-Defense & Self-Attribution of Blame \\
\hline Victim-Blaming & - & & \\
\hline Self-Defense & $.43^{* * *}$ & - & \\
\hline Self-attribution of blame & $-.20^{*}$ & -.06 & - \\
\hline Minimization & $.20^{*}$ & $.39^{* * *}$ & .14 \\
\hline
\end{tabular}

$* * \mathrm{p}<.05 . * * * \mathrm{p}<.001$.

suggest that participants in this study showed a tendency to blame the victim for their situation.

Regarding the Minimization scale, descriptive statistics also point to a similar direction. Except for the item $I$ am in this situation for doing things that in my family are considered unimportant $(\mathrm{M}=47.88)$, the levels of minimization tended to be low in the sample.

Finally, in Table 4 we present Pearson correlations among the three dimensions of Attribution of Responsibility and Minimization. The victim-blaming and self-defense dimensions were significantly related $(r=.43, \mathrm{p}<.001)$ suggesting that those participants who tended to blame the victim also showed a tendency to justify incidents as a matter of self-defense. Also, victim-blaming was negatively and significantly related with self-attribution of blame $(\mathrm{r}=-.20, \mathrm{p}<$ $.05)$, indicating that those respondents that blamed themselves also tended not to blame the victim. However, the relationship between self-attribution of blame and selfdefense was non-significant $(\mathrm{r}=-.06$, n.s. $)$, suggesting that these two dimensions are relatively independent. In other words, self-defense is a type of justification for the violent episode that appears at any level of self-attribution of blame.

Regarding Minimization, higher scores in this variable were related to higher levels of victim-blaming $(r=.20, p<$ $.05)$ and higher levels of self-defense $(r=.39, p<.001)$. Also, minimization seemed to be unrelated to self-attribution of blame ( $\mathrm{r}=.14, n . s$.). In other words, blaming the victim and justifying the behavior as an act of self-defense tended to appear in participants that also minimized the importance of their behavior towards the victim. For those who assumed the blame for the violent episode, their levels of minimization varied suggesting that these two variables are relatively independent.

\section{TWO-STEP CLUSTER ANALYSIS}

Finally, we analyzed the clustering of participants in the attribution of responsibility sub-scales and minimization scores. To do so, we used the two-step cluster analysis procedure implemented in SPSS 15. To determine the number of clusters automatically, SPSS uses the Bayesian Information Criterion (BIC). BIC is calculated for each number of clusters within a specified range to find the initial estimate for the number of clusters. At this stage, we used an initial range from 1 to 15 clusters. BIC is then used to evaluate the difference in model information, starting the comparison between a model with $n$ and a model with $n+1$ number of clusters, where $\mathrm{n}$ for the first comparison is 1 . The ratio of change in BIC determines the optimal number of clusters. This number of clusters is further refined by finding the largest relative increase in distance between the two closest clusters in each clustering stage. This procedure is adequate when the researcher wants to find the optimal number of groups that best represent the empirical distribution of data in the variables of interest. These variables were: victimblaming, self-defense, self-attribution of blame, and minimization.

In the first step, the number of clusters (or groups) that best fit the data is found. In our case, the number of groups were $n=2$. In the second step, each participant is assigned to a group. In Table 5, we present the two-step cluster analysis results, along with both multivariate and univariate tests of the mean differences between groups, as well as the means for each group.

The distribution of participants across the two groups indicates that group 1 is represented by $68.7 \%$ of participants while group 2 only represents one third of the sample $(31.3 \%)$. Looking at the average scores in each variable for

Table 5. Mean Group differences ${ }^{1}$ in Attribution of Responsibility and Minimization

\begin{tabular}{|c|c|c|c|c|c|}
\hline \multirow{2}{*}{} & \multirow{2}{*}{$\%$} & \multicolumn{3}{|c|}{ Attribution of Responsibility Scale } & \multirow{2}{*}{ Minimization Scale } \\
\cline { 3 - 6 } & & Victim-Blaming & Self-Defense & Self-Attribution of Blame & 21.1 \\
\hline \hline Group 1 & 68.7 & 44.8 & 13.3 & 23.3 & 24.7 \\
\hline Group 2 & 31.3 & $79.1^{\mathrm{a}}$ & $73.5^{\mathrm{a}}$ & $46.3^{\mathrm{a}}$ \\
\hline
\end{tabular}

${ }^{1}$ Multivariate Test (MANOVA): [F(4.110) = 80.91. $\left.\mathrm{p}<.001\right]$.

${ }^{\mathrm{a}}$ Group $2>$ Group 1, p <.001. Univariate test. 
group 1 we observe that, overall, participants in this group are characterized by lower levels of victim-blaming, selfdefense and minimization as compared to group $2[\mathrm{~F}(4.110)$ $=80.91 . \mathrm{p}<.001]$. The univariate test (not shown in Table 5) also reveals that there are statistically significant mean differences in all variables except for self-attribution of blame ( $\mathrm{F}=0.77$.n.s. $)$.

Thus, profile for group 2 indicates that almost one third of the sample not only blamed the victim and justified their behavior as an act of self-defense (means around the highend of the scale, $\geq 73$ ) but also they tended to minimize the behavior itself (mean $=46.3$ ). On the contrary, most of the sample (group 1) showed low levels of self-defense $($ mean = 13.3) and minimization $($ mean $=21.1)$ and medium levels of victim-blaming (mean $=44.8)$. For both groups, levels of self-attribution of blame were similar and low (means $\leq 25$ ).

\section{DISCUSSION}

In this study we have analyzed the attribution of responsibility of incidents of intimate partner violence in 119 male batterers attending to the first assessment session of a court mandated batterer intervention program in the community. The aim of the study was twofold: a) the analysis of the psychometric properties of two scales measuring attribution of responsibility and minimization; and b) the clustering of individuals regarding their levels of victim-blaming, selfdefense justifications, self-attributions of blame, and minimization to evaluate if there was any meaningful profile in attributions of responsibility and minimization for male batterers.

First, results showed that the 8-item Attribution of Responsibility Scale, that provides information about victimblaming (3.items), self-defense justifications (2 items) and self-attribution of blame ( 3 items), has an adequate internal consistency (Cronbach's alpha $=.70$ ) as well as their subscales (ranging from .60 to .79). Also, its factor structure clearly reflects the existence of three distinct dimensions theoretically relevant. Sub-scales scores are relatively independent of social desirability except for the self-attribution of blame dimension, whose score seems to be negatively and significantly related to social desirability. Thus, those participants more focused on showing a positive self-image also tended to show little agreement with the idea that they were responsible for their situation (convicted). Both victimblaming and self-defense dimensions were free of social desirability bias.

As for the Minimization Scale, comprised by four items evaluating the degree to which subjects minimize both the relevance and the severity of their behavior, the scale has showed a moderate internal consistency (Cronbach's alpha = .60). Scores on this scale are positively and significantly related with both victim-blaming and self-defense, suggesting that minimization might be accompanied by attributions that deny individual's responsibility. However, we did not find any statistical relationship between minimization and self-attribution of blame, indicating that the perception of severity for the violent episode does not seem to be linked to the assumption of responsibility. On the contrary, when minimization is high, participants tended to use external attributions (victim-blaming and self-defense) in order to explain their behaviors.
Consistent with prior studies [15-16, 19-21, 26-27, 29], high levels of external attributions of blame were found within our sample. The lower mean scores were obtained to self-attribution of blame items (mean scores from 18.4 to 29.2). Despite the fact that men in our sample had been arrested for and found guilty of assaulting his partner, the higher mean scores were found in items like I am here because of the lies and exaggerations of my partner, The aggressive character, lack of control, nervousness or psychological problems of my partner are the reasons why I am in this situation, and I am in this situation due to a false report items. All of these items refer to victim's lies, behavior or personality problems as responsible of their situation. Finally, another justification used by participants to a certain extent was that they acted in self-defense (I am here because $I$ defended my self from my partner's aggressions and I am in this situation because I acted in self-defense). These types of attributions characterize many perpetrators of IPVAW, and have to be taken into account in batterer programs interventions where participants "often do not perceive the existence of a problem, are rarely the ones to initiate treatment, are typically unwilling or disinterested participants in the change process, and face a wide array of criminal justice sanctions for treatment noncompliance" [54] (p. 329).

Second, the study has identified two types of participants in the program regarding their attribution of responsibility and minimization levels. The majority of participants (group $1,68.7 \%$ ) showed medium levels of victim-blaming and low levels of self-defense and minimization. The remaining participants (group 2, 31.3\%) showed high levels of both victim-blaming and self-defense and medium levels of minimization. For both groups, levels of self-attribution of blame were low. These results suggest that almost one third of participants maintained that their convicted status was due to the personal characteristics and aggressiveness of the victim. Also, these participants clearly disagreed with mainstream societal conceptions of domestic violence against women (minimization of proven facts). The majority of the participants (group 1) showed low levels in self-defense and minimization, and medium levels in victim-blaming. Although self-attribution of blame scores in this group are slightly higher than in group 2, they are very low too. The fact that all participants had low levels of self-attribution of blame could point to one of the priority areas of intervention. Since one of the main goals in batterer programs is that male offenders take responsibility of their behavior, the participants in group 2 clearly have an important need of intervention in this regard. Arguably, high levels of victim-blaming, selfdefense and minimization among participants may lead to disruptive behaviors during treatment sessions and an increased risk of abandoning the program [49].

While findings in this study suggest that both the attribution of responsibility and minimization scales might be useful, we should be cautious about the generalizability of results due to sample size. Also, the observed values on variables of the study corresponded to the first assessment session of a court mandated batterer intervention program in the community. Thus, it is unclear whether these attributions were present when the episode happened. Alternatively, these attributions could have changed during the time-lag between court's sentence and the assessment session at the beginning of the program. The availability of this informa- 
tion to researchers could be useful to assess participants' potential of change and therefore to focus on the special needs of each participant throughout the program. This is especially relevant in intervention programs that seek to promote stable and deep changes in attribution of responsibility and minimization. For example, in severe cases, the professionals may need to consider different methods for motivating participants. For these cases, participants might benefit from previous intervention efforts to increase readiness for treatment [55].

Another potential limitation is that in our study we did not take into account underlying variables that could be explaining the low levels of self-attribution of blame observed among all participants. It could be that dispositional factors had been accounting for low self-attribution of blame levels. In this regard, White and Gondolf [56] had shown a preponderance of narcissistic and antisocial tendencies among batterers using the psychological profiles generated by the Millon Clinical Multiaxial Inventory (MCMI-III) [57]. A research review on violent offenders in general showed that inflated expectations, "self-righteousness", and threatened egotism characterized the vast majority of these men [58]. According to Gondolf [59], many violent people, especially those with antisocial and narcissistic tendencies, do not feel much guilt or personal responsibility for their violent behavior. They are likely to blame other individuals or outward circumstances. In this regard, according to Henning and Holdford [15] it is important to assess these dispositional variables. Furthermore, Paulhus [60] makes a distinction between response biases for the purpose of impression management as opposed to self-deception. In the case of impression management there is conscious manipulation of responses in order to appear more socially conforming. This can be originated by situational pressures or shame about violent behavior. In the case of self-deception, individuals actually believe their positive self-reports to be accurate. These individuals often have an inflated self-esteem and tend to blame others for their behavior and to believe that the severity of their actions has been exaggerated. More research is needed to disentangle the effects of dispositional and situational factors on attribution of responsibility and minimization [32].

Beyond these potential limitations, the results presented here might be useful to identify priority areas of intervention in convicted males for domestic violence against women.

\section{ACKNOWLEDGEMENTS}

Support for this research was provided by a grant from the Spanish Ministry of Work and Social Affairs (MUJER2007-PI-090).

\section{REFERENCES}

[1] World Health Organization (2002). World report on violence and health. Geneva: Author.

[2] American Medical Association. (1994). Diagnostic and treatment guidelines on domestic violence. Chicago: Author.

[3] Bachman R, Saltzman L. (1995). Bureau of Justice Statistics special report: Violence against women: Estimates from the redesigned survey (NCJ-154348). Washington, DC: U.S. Department of Justice, Bureau of Justice Statistics.

[4] Council of Europe. (2002). Recommendation Rec (2002)5 of the Committee of Ministers to member states on the protection of women against violence adopted on 30 April 2002 and explanatory memorandum. Strasbourg, France: Author.
[5] Hagemann-White C. European research on the prevalence of violence against women. Violence Against Women 2001; 7: 732-59.

[6] Kury H, Obergfell-Fuchs J, Woessner G. The extent of family violence in Europe. Violence Against Women 2003; 10: 749-69.

[7] Gracia E, Herrero J. Public attitudes toward reporting partner violence against women and reporting behavior. J Marriage Fam 2006a; 68: 759-68. http://www.uv.es/ egracia/enriquegracia/docs/ scanner/jomf_288.pdf.

[8] Gracia E, Herrero J. Acceptability of domestic violence against women in the European Union: A multilevel analysis. J Epidemiol Commun Health 2006b; 60: 123-29.

[9] Gracia E, Herrero J. Perceived neighborhood social disorder and attitudes toward reporting domestic violence against women. J Interpers Violence 2007; 22: 737-52.

[10] Instituto de la Mujer (2000). La violencia contra las mujeres. Resultados de la macroencuesta. I Parte [Violence against women. Results from the macrosurvey, Part I]. Madrid, Spain: Author.

[11] Instituto de la Mujer (2003). La violencia contra las mujeres. Resultados de la macroencuesta. II Parte [Violence against women. Results from the macrosurvey, Part II]. Madrid, Spain: Author.

[12] Medina-Ariza J, Barberet R. Intimate partner violence in Spain. Violence Against Women 2003; 9: 302-22.

[13] Stith SM, Green NM, Smith DB, Ward DB. Marital satisfaction and marital discord as risk markers for intimate partner violence: A Meta-analytic review. J Fam Violence 2008; 23: 149-60.

[14] Heckert DA, Gondolf EW. Assessing assault self-reports by batterer program participants and their partners. J Fam Violence 2000; 15(2): 181-97.

[15] Henning K, Holdford R. Minimization, denial, and victim blaming by batterers: How much does the truth matter? Crim Justice Behav 33: 2006; $110-30$.

[16] Henning K, Jones AR, Holdford, R. "I didn't do it, but if I did I had a good reason": Minimization, denial, and attributions of blame among male and female domestic violence offenders. J Fam Violence $2005 ; 20(3)$ : 131-39.

[17] Lila M, Gracia E, Herrero J. Self-attributions and external attributions of male batterers in court mandated programs. Paper presented at The First Biennial Conference of the International Family Aggression Society, 2008; Preston, England.

[18] Scott K, Straus, M. Denial, minimization, partner blaming, and intimate aggression in dating partners. J Interpers Violence 2007; 22: 851-71.

[19] Bograd M. How battered women and abusive men account for domestic violence: Excuses, justifications, or explanations? In Hotaling G, Finkelhor D, Kirkpatrick J, Straus M, Eds. Coping With Family Violence: Research and Policy Perspectives, 1988; (pp. 6077). Thousand Oaks, CA: Sage.

[20] Cantos A, Neidig P, O'Leary KD. Men and women's attributions of blame for domestic violence. J Fam Violence 1993; 8: 289-02.

[21] Dutton D. Wife assaulter's explanations for assault: The neutralization of self-punishment. Can J Behavioral Sci 1986; 18: 381-90.

[22] Eckhardt C, Dye M. The cognitive characteristics of maritally violent men: Theory and evidence. Cogn Ther Res 24: 2000; 13958.

[23] Holtzworth-Munroe A, Hutchinson G. Attributing negative intent to wife behavior: The attributions of maritally violent versus nonviolent men. J Abnorm Psychol 1993; 102: 206-11.

[24] Barnett OW, Martinez TE, Bluestein BW. Jealousy and romantic attachment in maritally violent and nonviolent men. J Interpers Violence 1995; 10: 473-86.

[25] Holtzworth-Munroe A, Anglin K. The competency of responses given by maritally violent versus nonviolent men to problematic marital situations. Violence Vict 1991; 6: 257-69.

[26] Dutton D, Hemphill K. Patterns of socially desirable responding among perpetrators and victims of wife assault. Violence Vict 1992; 7: 29-39.

[27] Hamberger K. Cognitive behavioral treatment of men who batter their partners. Cogn Behavioral Pract 1997; 4: 147-69.

[28] Edin KE, Lalos A, Högberg U, Dahlgren L. Violent men: ordinary and deviant. J Interpers Violence 2008; 23: 225-44.

[29] Saunders D. Procedures for adjusting self-reports of violence for social desirability bias. J Interpers Violence 1991; 6: 336-44.

[30] Fowers BJ, Lyons EM, Montel KH. Positive marital illusions: Selfenhancement or relationship enhancement? J Fam Psychol 1996; 10: $192-08$. 
[31] Schaefer-Porter RL, Hendrick SS. Attributions, behavioral reactions and relationship satisfaction. Fam Ther 2000; 27: 1-18.

[32] Sugarman D, Hotaling, G. Intimate violence and social desirability: A meta-analytic review. J Interpers Violence 1997; 12: 275-90.

[33] Healey K, Smith C, O’Sullivan C. (1998). Batterer intervention: Program approaches and criminal justice strategies. Washington: National Institute of Justice.

[34] Austin J, Dankwort J. Standards for batterer programs: A review and analysis. J Interpers Violence 1999; 14: 152-68.

[35] Pence E, Paymar M. (1993). Education groups for men who batter: The Duluth model. New York: Springer.

[36] Davis R, Taylor B. Does batterer treatment reduce violence? A synthesis of the literature. Women Criminal Justice 1999; 10: 6993.

[37] Gondolf EW. (2002). Batterer intervention systems. Issues, outcomes, and recommendations. London: Sage.

[38] Edelson J. Working with men who batter. Soc Work 1984; 29: 23742.

[39] Kropp PR, Hart S, Webster C, Eaves D. (1995). Manual for the Spousal Assault Risk Assessment Guide (2nd ed.). Vancouver, Canada: B.C. Institute on Family Violence.

[40] Hanson RK, Wallace-Capretta S. (2000). Predicting recidivism among male batterers (User Report 2000-06). Ottawa: Department of the Solicitor General of Canada.

[41] Grann M, Wedin I. Risk factors for recidivism among spousal assault and spousal homicide offenders. Psychol Crime Law 2002; 8: 5-23.

[42] Dutton DG, Starzomski AJ. Personality predictors of the Minnesota Power and Control Wheel. J Interpers Violence 1997; 12: 70-82.

[43] Eckhardt CI, Barbour KA, Davison GC. Articulated thoughts of martially violent and nonviolent men during anger arousal. J Consult Clin Psychol 1998; 66: 259-69.

[44] Schweinle WE, Ickes W, Bernstein IH. Empathetic inaccuracy in husband to wife aggression: The overattribution bias. Personal Relationships 2002; 9: 141-58.

[45] Tonizzo S, Howells K, Day A, Reidpath D, Froyland I. Attributions of negative partner behavior by men who physically abuse their partners. J Fam Violence 2000; 15: 155-67.
[46] Ehrensaft MK, Vivian D. Is partner aggression related to appraisals of coercive control by a partner. J Fam Violence 199914: 251-66.

[47] Arias I, Johnson P. Evaluations of physical aggression among intimate dyads. J Interpers Violence 1989; 4: 298-07.

[48] Cauffman E, Feldman SS, Jensen LA, Arnett JJ. The (un)acceptability of violence against peers and dates. J Adolescent Research 2000; 15: 652-73.

[49] Daly J, Pelowski S. Predictors of dropout among men who batter: Are view of studies with implications for research and practice. Violence Vict 2000; 15: 137-60.

[50] Murphy CM, Baxter VA. Motivating batterers to change in the treatment context. J Interpers Violence 1997; 12: 607-19.

[51] Scott KL, Wolfe DA. Readiness to change as a predictor of outcome in batterer treatment. J Consult Clin Psychol 2003; 71: 87989.

[52] Holtzworth-Munroe A, Bates L, Smutzler N. Sandin E. A brief review of the research on husband violence: Part I, Maritally violent versus nonviolent men. Aggresion Violent Behav 1997; 2: 65 99.

[53] Crowne D, Marlowe D. (1964). The approval motive: Studies in adaptive dependence. New York: Wiley.

[54] Eckhardt CI, Utschig AC. Assessing readiness to change among perpetrators of intimate partner violence: Analysis of two selfreport measures. J Fam Violence 2007; 22: 319-30.

[55] Tolman R, Bhosley G. A comparison of two types of pregroup preparation for men who batter. J Soc Serv Res 1989; 13: 33-43.

[56] White R, Gondolf, E. Implications of personality profiles for batterers treatment. J Interpers Violence 2000; 15: 467-88.

[57] Millon T. (1994). Manual for the MCMI-III. Minneapolis, MN: National Computer Systems.

[58] Baumeister R, Smart L, Boden J. Relation of threatened egotism to violence and aggression: The dark side of high self-esteem. Psychol Rev 1996; 103: 5-33.

[59] Gondolf EW. Theoretical and research support for the Duluth Model: A reply to Dutton and Corvo. Aggresion Violent Behav 2007; 12: 644-57.

[60] Paulhus DL. Two-component models of socially desirable responding. J Pers Soc Psychol 1984; 46: 598-09. 